\title{
Article \\ Sodium Iodide as a Contrast Agent for X-ray Micro-CT of a Wood Plastic Composite
}

\author{
Dengcheng Feng ${ }^{1, *} \mathbb{D}$, Michael Turner ${ }^{2}$ and Philip D. Evans ${ }^{1,2, *}$ \\ 1 Department of Wood Science, Faculty of Forestry, University of British Columbia, \\ Vancouver, BC V6T 1Z4, Canada \\ 2 ARC Training Centre for M3D Innovation, Department of Applied Mathematics, Research School of Physics, \\ The Australian National University, Canberra, ACT 0200, Australia; Michael.turner@anu.edu.au \\ * Correspondence: michaelfeng1995@foxmail.com (D.F.); phil.evans@ubc.ca (P.D.E.); Tel.: +1-604-822-0517 (D.F.)
}

check for updates

Citation: Feng, D.; Turner, M.; Evans, P.D. Sodium Iodide as a Contrast Agent for X-ray Micro-CT of a Wood Plastic Composite. Appl. Sci. 2022, 12, 208. https://doi.org/10.3390/app 12010208

Academic Editors: Réh Roman, Petar Antov and L'uboš Krišt'ák

Received: 29 November 2021 Accepted: 23 December 2021 Published: 26 December 2021

Publisher's Note: MDPI stays neutral with regard to jurisdictional claims in published maps and institutional affiliations.

Copyright: (C) 2021 by the authors. Licensee MDPI, Basel, Switzerland. This article is an open access article distributed under the terms and conditions of the Creative Commons Attribution (CC BY) license (https:// creativecommons.org/licenses/by/ $4.0 /)$.

\begin{abstract}
The properties of wood plastic composites (WPCs) depend on their microstructure, particularly the level and geometry of wood reinforcement in the composite. We hypothesize that impregnating a WPC with a radiocontrast agent will increase the contrast between wood and plastic, allowing better visualization of its microstructure and numerical analysis of the geometry of its wood reinforcement. A commercial WPC was scanned using X-ray micro-CT, impregnated with aqueous sodium iodide, and then rescanned. CT data from both scans were visualized, and we analyzed the geometry of wood reinforcement and levels of wood, plastic, zinc borate (ZB), and voids in the WPC. ZB occurred mainly as discrete particles between wood flakes, and interfacial voids formed a network of cracks within the WPC. Sodium iodide labeling made it possible to clearly visualize wood and plastic in the WPC and quantify levels of different phases and the geometry of wood particles. However, sodium iodide was not an ideal contrast agent because it swelled wood particles, closed interfacial voids, and partially dissolved ZB particles. We suggest methods of overcoming these limitations and conclude that advances in labeling are necessary to improve our understanding of the relationship between the microstructure of WPCs and their properties.
\end{abstract}

Keywords: wood plastic composite; zinc borate; X-ray microcomputed tomography; contrast agent; sodium iodide; particle geometry

\section{Introduction}

Wood plastic composites (WPCs) are an important class of natural fiber-reinforced composites, and in North America alone, approximately $2000 \mathrm{Kt}$ of WPCs are produced each year, with an estimated market value of USD 6 billion [1]. WPCs consist of a commodity polymer (most commonly high-density polyethylene, 35-45\%), comminuted wood $(50-60 \%)$, and various additives (5\%) [2]. The wood in WPCs is a heterogeneous mix of particles that vary in size ( 0.1 to $2 \mathrm{~mm}$ in length and 0.1 to $0.6 \mathrm{~mm}$ in width), geometry, microstructure, and chemical composition [3]. The size of wood particles in WPCs influences composite performance; for example, WPCs containing larger particles of wood are more susceptible to decay by basidiomycete fungi than composites containing smaller particles [4]. Smaller wood particles act as a filler in WPCs, but larger particles provide reinforcement [2]. Hence, tailoring the size and geometry of particles can improve the mechanical properties of WPCs. For example, previous studies have examined the relationships between the initial size and length-to-width ratio of wood particles (measured using microscopy) and the mechanical properties of WPCs $[5,6]$. These studies have shown that when wood particles have a larger aspect ratio, 'there is potential for more effective load transfer between the plastic and particles leading to better mechanical properties' [7]. However, the geometry of particles changes when they are incorporated into WPCs, and, hence, measurements of particle dimensions prior to processing may not reflect their dimensions within manufactured WPC [8]. In addition, and more generally, as pointed out 
by Hanhan et al. [9], prediction of the properties of polymer composites requires accurate characterization of their microstructural features. Various techniques have been used to characterize the microstructure of composites, including light and electron microscopy, ultrasound imaging, NMR and IR imaging, and various X-ray imaging techniques [10-13].

$\mathrm{X}$-ray microcomputed tomography $(\mathrm{CT})$ is increasingly used to characterize the microstructure of polymer and aerospace composites and examine either experimentally or computationally the relationship between microstructure and bulk composite properties [13,14]. X-ray micro-CT has also been used to characterize the microstructure of wood composites, including wood plastic composites [3,15-20]. Characterization of wood plastic composites using X-ray micro-CT is challenging because, as pointed out by Wang et al. [3], 'plastics and wood are both weak in X-ray attenuation, and this always causes insufficient contrast in X-ray images and inability to separate wood particles from plastic'. Wang et al. [21] incorporated gold nanoparticles into a WPC to improve the contrast between wood and plastic in a laboratory-made composite. Alternative methods used to make it easier to distinguish wood and plastic are to reduce the wood particle fraction in the WPC or subsample volumes and select larger wood particles that are easier to threshold [8]. Nevertheless, it is challenging to distinguish plastic from small wood particles and discern interfacial regions within WPCs, as pointed out by Krause et al. [8]. Hence, better methods of increasing the contrast between wood and plastic in WPCs are needed. One obvious approach is to label either the plastic or the wood component to increase their X-ray opacity. In previous research, we successfully labeled the thermosetting polymer adhesive, melamine-urea formaldehyde with copper sulfate to distinguish it from wood in particleboard [16]. Similarly, barium sulfate or iodine have also been used as X-ray contrast agents for urea formaldehyde resin in medium-density fiberboard [22]. However, these approaches are only suitable for laboratory-made boards. For commercial particleboard, we took the opposite approach and labeled the wood rather than the polymer by injecting particleboard with the halogenated, low-viscosity, X-ray-opaque solvent bromoform $\left(\mathrm{CHBr}_{3}\right)$ [23]. This approach was only partially successful because the bromoform did not completely penetrate the composite [23]. Nevertheless, in areas where wood particles absorbed bromoform, it was possible to distinguish wood from polymer [23]. Hence, we hypothesize that thoroughly impregnating a WPC with a halogenated fluid will be able to increase the contrast between wood and plastic, allowing better visualization of the microstructure of the WPC and numerical analysis of the geometry of particles in the WPC. The aim of the work was to test this hypothesis, describe new insights into the microstructure of WPCs (if any), and compare our approach and results with those of other researchers who have examined the effects of wood reinforcement on the properties of WPCs.

\section{Materials and Methods}

\subsection{Wood Plastic Composite Sample and Initial X-ray Micro-CT}

An uncapped sample of wood plastic composite (WPC) decking measuring $24 \mathrm{~mm}$ (thick) and $140 \mathrm{~mm}$ squared provided by Rio Tinto was air freighted to the University of British Columbia. The WPC was composed of a polyethylene polymer, wood particles, zinc borate, and other unspecified additives. However, the relative proportions of the different components in the WPC sample, including the wood fraction, were not known. A cylindrical core $(5.8 \mathrm{~mm}$ (diameter) $\times 9.68 \mathrm{~mm}($ length $)$ ) was removed from the WPC sample using a plug cutter and vertical drill press. The sample was wrapped in pliable plastic, air-bubble packaging and sealed in a padded envelope, which was air freighted by courier to the National Laboratory for X-ray Micro-Computed Tomography at The Australian National University in Canberra. The sample was sealed in a polyether ether ketone (PEEK) tube and imaged using a helical cone-beam X-ray micro-CT device designed and built in the Department of Applied Mathematics at the Australian National University [24]. The sample was fixed to the stage of the X-ray micro-CT device. X-rays from a cone-beam source passed through the sample to a detector, where they created a two-dimensional radiograph 
of the sample's interaction with X-rays. A series of 2880 such projections were collected over a period of $16 \mathrm{~h}$ by rotating and moving the sample relative to the $\mathrm{X}$-ray source. The resolution of the CT scan was $2600 \times 2600$ voxels with a voxel size of $3.1 \mu \mathrm{m}$. Projection data were used to create 3D volumes (tomograms) of the X-ray attenuation property of the sample. Projection data were segmented to identify discrete phases in the WPC (wood, plastic, void space, and zinc borate).

\subsection{Impregnation of WPC Sample with Sodium Iodide and X-ray Micro-CT}

A $0.2 \mathrm{~mol} / \mathrm{L}$ aqueous solution of sodium iodide (NaI) was used as a contrast agent for the WPC sample. Following the initial X-ray CT scan described above, the cylindrical WPC sample was placed in a stainless-steel pressure vessel containing sodium iodide solution under $41.37 \mathrm{MPa}$ of pressure. After 10 days, the WPC sample was removed from the pressure vessel and sealed within a PEEK tube, containing free NaI fluid at the bottom of the tube. This reservoir of liquid ensured that the WPC sample did not dry out and move when it was irradiated with X-rays. The PEEK tube containing the WPC sample was placed on the rotating stage of a helical X-ray micro-CT device (as above) for $5 \mathrm{~h}$ prior to scanning. The sample was then scanned for $25 \mathrm{~h}$, and projection data were segmented as described above for the first scan.

\subsection{Visualization and Numerical Analysis of Different Phases in WPC Sample}

Phases in tomograms from the scans of the WPC sample before and after impregnation with sodium iodide $(\mathrm{NaI})$ were visualized using the volume rendering software Drishti, which assigns colors and transparency to voxels (3D pixels) based on their intensity value [25]. Drishti was used to create 2D images and 3D animations of the WPC sample. Numerical analyses of volumes of different phases in the WPC sample used the software Avizo (Thermo Fisher Scientific, Waltham, MA, USA). For the analysis of phase volumes, the central region ( $2.56 \mathrm{~mm}$ long) of the untreated cylindrical core, which had the best contrast, was selected. The matching region within the NaI-impregnated core was also selected. Both data sets were thresholded, and the percentages of the different phases were calculated. The wood volume from the second data set was adjusted to account for the swelling of wood caused by NaI. This adjustment involved the following. First, calculation of the plastic content of the WPC before impregnation, which is assumed to remain constant as a result of labeling, is required (1):

$$
P_{0}(\%)=\frac{V_{P W 0}-\frac{V_{W 1}}{1+S^{W}}}{V_{0}}
$$

where $P_{0}$ is the plastic content before impregnation, $V_{0}$ is the total volume before impregnation, $V_{P W 0}$ is the volume of plastic and wood before impregnation, $V_{W 1}$ is the wood volume after impregnation, and $S^{W}$ is the swelling ratio of wood. According to Siau [26], $S^{W}$ can be calculated using Equation (2):

$$
S^{W}=\left(M_{f}-M_{0}\right) G_{0}^{w}
$$

where $M_{f}$ is the moisture content of wood at the saturation point, $M_{0}$ is the moisture content of the wood before impregnation, and $G_{0}^{w}$ is the specific gravity of the wood cell wall substance. Equation (1) can then be modified as follows:

$$
P_{0}(\%)=\frac{V_{P W 0}}{V_{0}}-\frac{V_{W 1}}{V_{0}+\left(M_{f}-M_{0}\right) G_{0}^{w} V_{0}}
$$

$V_{P W 0}, V_{0}$, and $V_{W 1}$ were obtained from the X-ray CT scan. Given that the initial moisture of wood in WPC is $~ 1-1.5 \%$ [27], we assume $M_{f}=30 \%, M_{0}=1.5 \%$, and $G_{0}^{w}=1.53$. The plastic content was then calculated as $35.10 \%$. The adjusted proportions of the components before impregnation are shown in Table 1. 
Table 1. Volumes $\left(\mathrm{mm}^{3}\right)$ of phases in the WPC sample (percentage in parenthesis).

\begin{tabular}{cccc}
\hline Composition/Phases & Before Labeling & After Labeling & Adjusted * \\
\hline Voids within WPC & $5.1(8.5 \%)$ & - & $5.1(8.5 \%)$ \\
Wood particles & - & $46.2(65.6 \%)$ & $32.2(54.1 \%)$ \\
Plastic matrix & - & - & $20.9(35.1 \%)$ \\
Zinc borate & $1.4(2.29 \%)$ & $0.39(0.56 \%)$ & $1.4(2.3 \%)$ \\
biocide/fire retardant & &
\end{tabular}

To calculate the extent of the interconnected void network, we used Avizo's label analysis module, which measured the percentage volume of the largest 3D object representing voids. The same module was used to calculate the percentage of wood particles that were connected. In addition, Avizo was used to calculate the number and sizes of the zinc borate particles before and after impregnation of the WPC sample. A series of 760 continuous 2D tomograms were selected from the central region of the WPC core before impregnation, and a matching series of tomograms were selected from the core after treatment. Analysis of variance was used to analyze the effect of $\mathrm{NaI}$ impregnation on the number and sizes of zinc borate particles in the WPC sample. Statistical computation used Genstat (v. 20) (VSN International, Hemel Hempstead, UK).

\subsection{Numerical Analysis of Geometry of Wood Particles in WPC Sample}

A volume within the labeled WPC sample data set, measuring $4.92 \mathrm{~mm}$ (diameter) $\times 0.64 \mathrm{~mm}$ (thickness), was selected using Avizo. All wood particles in this area were labeled, except those on the edges of the volume that were cut during sample preparation. Labeling of wood particles involved thresholding them, smoothing thresholded volumes, and filling pores for easier segmentation. Secondly, thresholded volumes were divided into small 3D segments based on the topological skeleton of wood particles [28]. Finally, all wood particles were labeled according to the following rules: (1) particles that contained more than one segment (Figure 1, blue), were only labeled on one segment, which was usually the central or the largest particle of wood (Figure 1, labeled in blue); (2) particles that were wholly separated from other particles and only contained one segment were fully tagged (Figure 1, green); (3) particles that were attached to other particles were manually labeled in their centers (Figure 1, magenta). The tags were numbered, and 50 of them were randomly selected. The selected wood particles were manually traced to obtain their complete dimensions (Figure 1d).

The volume, surface area, aspect ratio, and Wadell circularity [29] of wood particles were measured using Avizo. We used the definition of aspect ratio from Merkus [30], which is the maximum Feret diameter divided by the minimum Feret diameter. Particle length $(\mathrm{L})$ is the largest Feret diameter of a wood particle, breadth (B) is the largest Feret diameter perpendicular to $\mathrm{L}$, and thickness $(\mathrm{T})$ is the largest Feret diameter perpendicular to both $\mathrm{L}$ and B. The L:B:T ratios were calculated to obtain a shape parameter. 

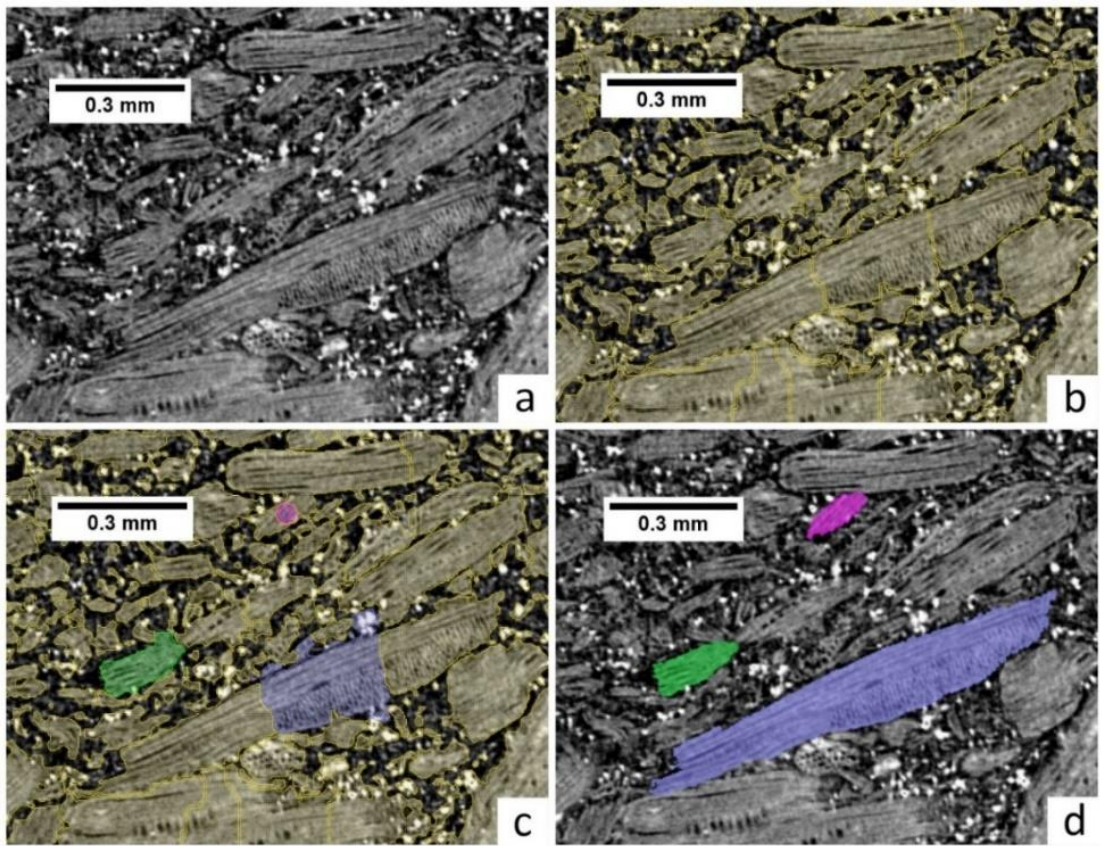

Figure 1. Labeling and restoration of wood particles. (a) Original grayscale tomogram; (b) thresholded volume showing segments (yellow); (c) three different types of labels: blue, a wood particle with more than one segment; green, a particle with only one segment; magenta, an unseparated particle that shared a segment with another particle. (d) Results of the manual restoration of labeled particles.

\section{Results}

\subsection{Visualization of Phases in WPC before and after Impregnation with NaI}

Impregnation of the WPC sample with sodium iodide made it possible to clearly differentiate wood and polymer as hypothesized. Before impregnation of the WPC sample, it was possible to clearly identify air and zinc borate, which are colored light blue and white in Figure 2a,c,e, respectively, but there was a lack of contrast between wood and plastic. In particular, it was difficult to distinguish smaller wood particles from the plastic matrix. However, larger wood particles could be seen in the unimpregnated sample because of their cellular characteristics. As a result, it was possible to see that the WPC contained both softwood (Figure 2a, arrowed) and hardwood particles (Figure 2c, arrowed).

The unimpregnated sample contained voids within and around wood particles, particularly larger particles, whereas such voids were absent from the impregnated sample. Interfacial voids around particles in the unimpregnated sample were connected creating a network of cracks within the WPC (Figure 2e). Numerical analysis of the network revealed that $61.8 \%$ of the voids formed a single connected network. A similar analysis revealed that almost all (99.75\%) of the wood particles in the WPC were connected. As expected, zinc borate ( $\mathrm{ZB})$ was easy to see in the unimpregnated sample because it is far denser than plastic or wood. ZB occurred mainly as discrete particles between rather than within or around wood particles (Figure 2). However, occasionally, large wood particles were encased in a layer of zinc borate particles (Figure 2c,d). Zinc borate particles were clearly smaller and less numerous in the WPC sample after it was impregnated with sodium iodide. Accordingly, analysis of variance showed a highly significant $(p<0.001)$ effect of impregnation with sodium iodide on the number of ZB particles and their average diameter in the selected volume within the WPC. These observations are supported by analysis of $\mathrm{ZB}$ particles in the entire data set, which showed that the number of particles decreased from 1,130,639 to 512,731 as a result of labeling. Similarly, the average volume and diameter of the ZB particles dropped from $1204.4 \mu \mathrm{m}^{3}$ and $10.4 \mu \mathrm{m}$ (before labeling) to $770.8 \mu \mathrm{m}^{3}$ and $8.8 \mu \mathrm{m}$, respectively, after labeling. 

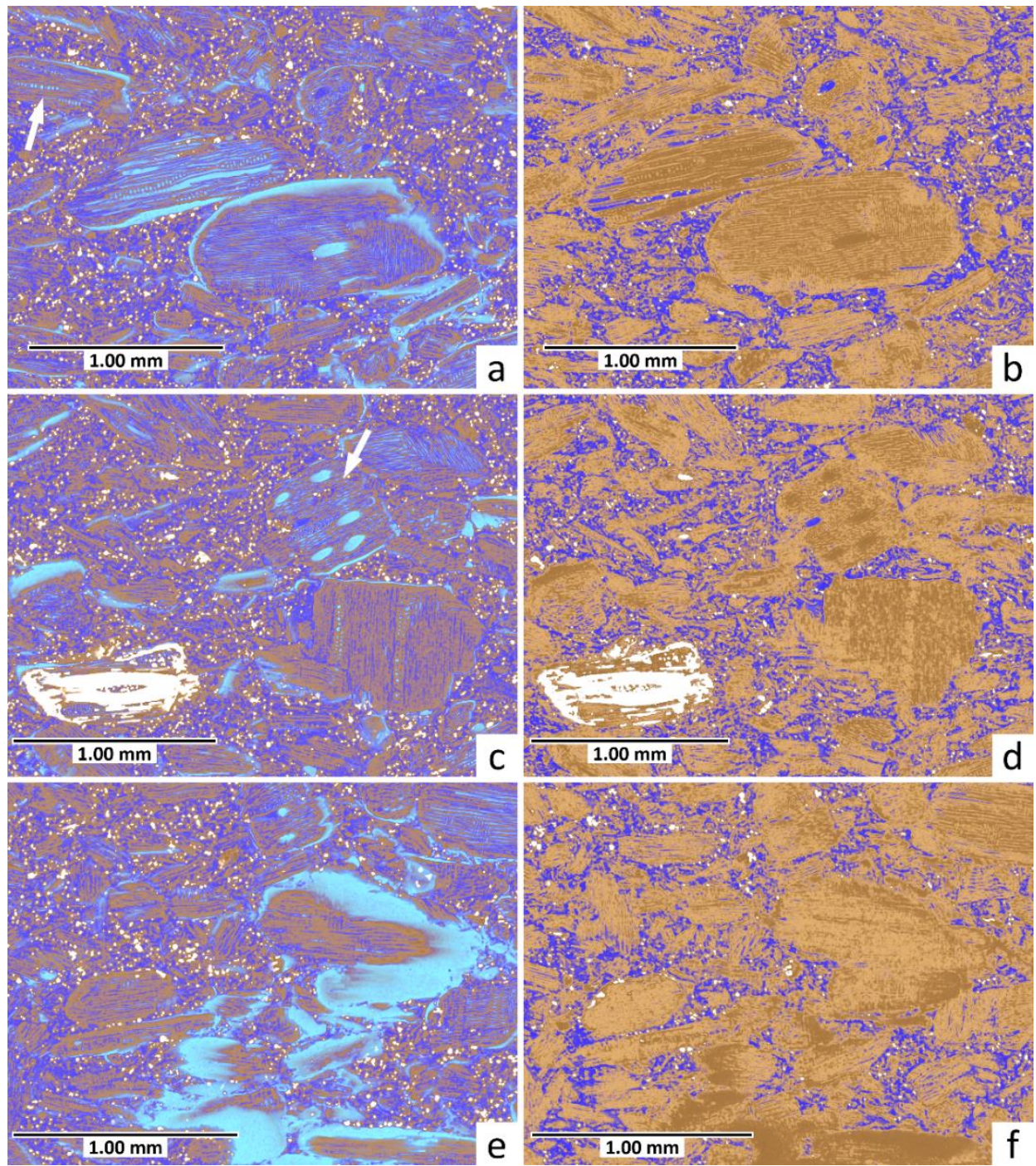

Figure 2. Two-dimensional (2D) tomographic images of the wood plastic composite: before (a,c,e) and after $(\mathbf{b}, \mathbf{d}, \mathbf{f})$ impregnation with sodium iodide; brown = wood; navy blue = plastic; light blue = void; white $=$ zinc borate

The improved contrast between wood and polymer in the impregnated sample made it possible to see two features that were not apparent in the unimpregnated sample. Firstly, there were areas where wood particles met that contained little or no polymer (Figure 3a,b). Secondly, wood particles in the WPC were not randomly oriented. Instead, many of the larger particles were oriented in approximately the horizontal direction in length (Figure 3c,d). 

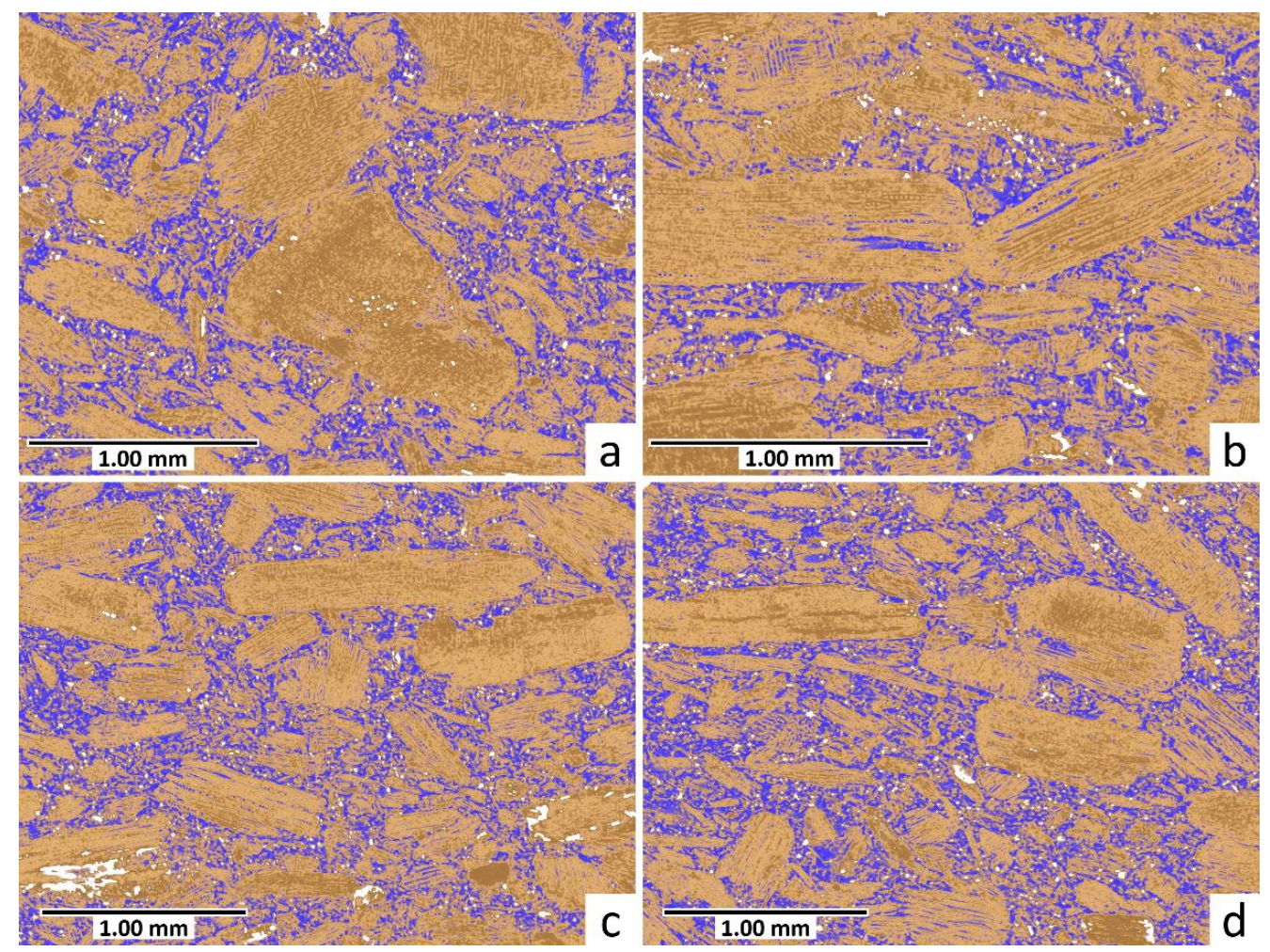

Figure 3. Tomographic images of the wood plastic composite after it was impregnated with sodium iodide showing wood-to-wood connections $(\mathbf{a}, \mathbf{b})$ and orientation of particles in the sample $(\mathbf{c}, \mathbf{d})$.

\subsection{Quantification of Different Phases in WPC following Labeling with NaI}

It was not possible to segment wood and plastic in the unlabeled WPC, as mentioned above, but after impregnation with sodium iodide, there was sufficient contrast to segment both phases. However, swelling of wood particles caused by aqueous sodium iodide solution, which is obvious in Figure $2 \mathrm{~b}, \mathrm{~d}, \mathrm{f}$, altered the volumetric composition of the WPC. Therefore, quantification of the levels of wood and plastic in the labeled WPC required adjustment of the wood content for such swelling, as described above.

Finally, compositional volumes of the WPC after impregnation with sodium iodide needed to be adjusted to reflect the natural composition of the WPC, including the void and zinc borate, which were altered by the labeling process (Table 1 ). The adjusted volumes in Table 1 indicate that the WPC was mainly composed of wood (54\%) and plastic (35\%), in accordance with figures in the literature [31], but the void volume was significant (8.5\%).

\subsection{Quantification of Wood Particle Sizes and Geometry}

The particles that were randomly selected in a slice within the labeled WPC sample are shown in Figure 4. There is clearly great variation in the size and geometry of the particles. This was confirmed by using Avizo software to quantify: (1) the largest Feret diameter of each wood particle (length, L); (2) breadth (B) as the largest Feret diameter perpendicular to $\mathrm{L}$; and (3) thickness (T) as the largest Feret diameter perpendicular to both $\mathrm{L}$ and B. Shape was defined using a combination of $\mathrm{L}, \mathrm{B}$, and $\mathrm{T}$, as mentioned above. 


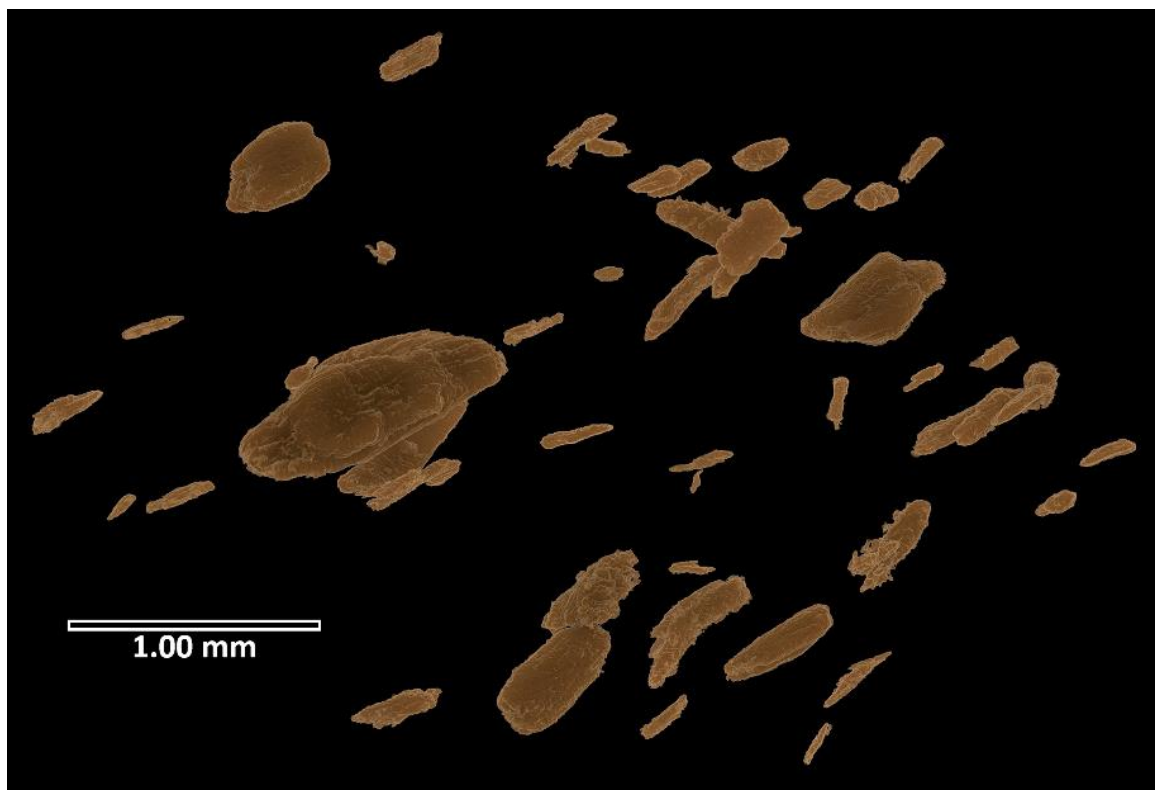

Figure 4. Images of each of the wood particles that were randomly selected from a volume within the labeled WPC sample.

All of the selected wood particles were longer than they were wide (Figure 5). Three particles had an aspect ratio slightly greater than two, i.e., similar to the rectangular format of films (movies) used to depict landscapes. Four particles $(8 \%)$ had needle-like aspect ratios of $>5$.
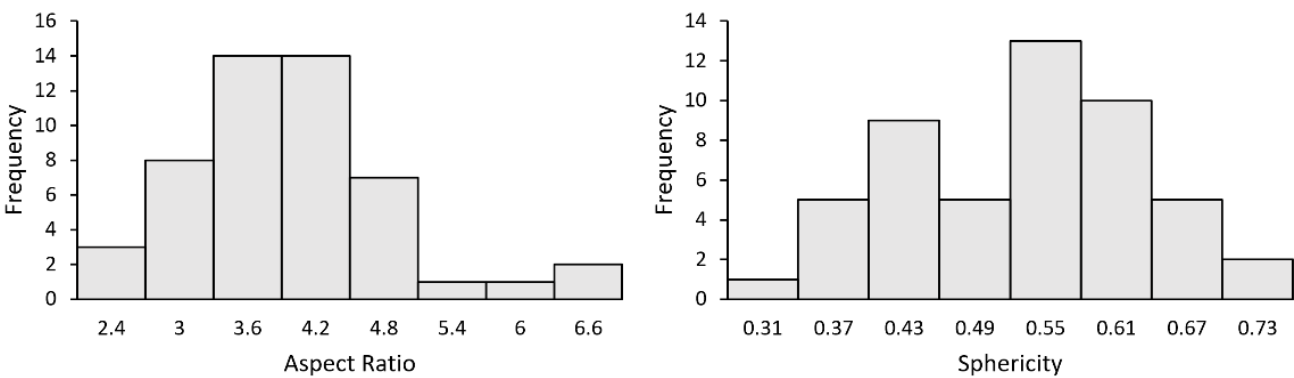

Figure 5. Aspect ratios and sphericity of the wood particles that were randomly selected from a slice within the labeled wood plastic composite sample.

Shape descriptions based on Ferret L:B:T values showed that most of the wood particles were either columns or plates (Figure 6). None of the particles could be classified as spheres, i.e., particles with diameter deviations within $5 \%$, rotational symmetry, and round surfaces [30]. The unclassified category in Figure 6 is composed of particles that do not fit any of the categories developed by Merkus [30]. 


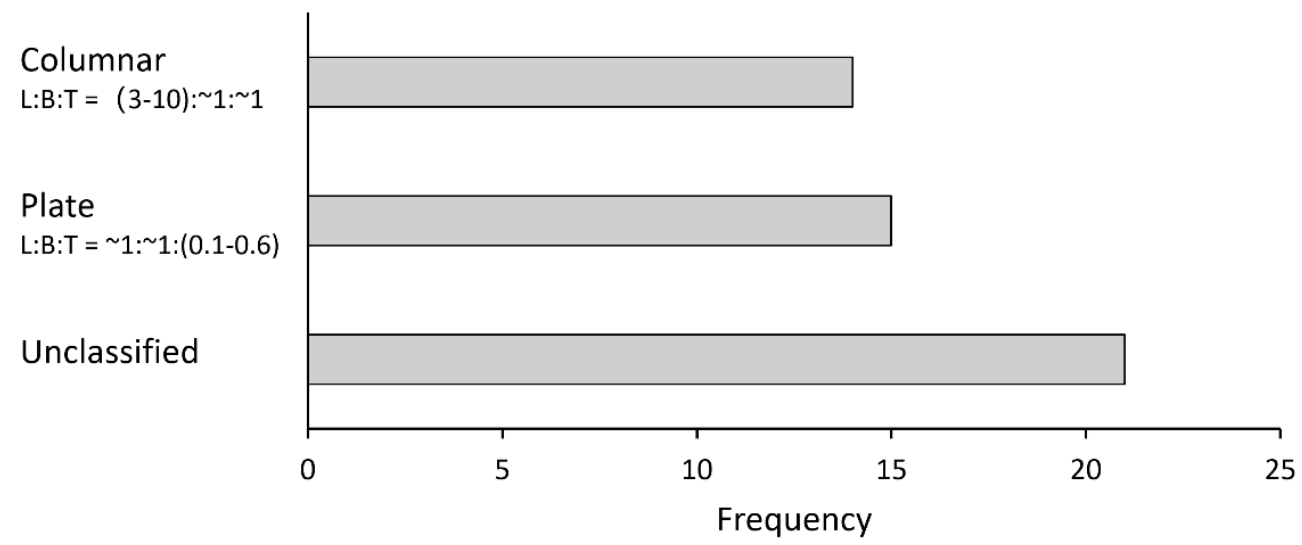

Figure 6. Shape descriptions of the selected 50 particles based on their length, breadth, and thickness (L:B:T) ratios.

\section{Discussion}

Our results only partially support our hypothesis that aqueous sodium iodide is a suitable X-ray micro-CT contrast agent to help visualize the microstructure of a wood plastic composite. Sodium iodide labeling made it possible to: more clearly visualize wood and plastic in the WPC, quantify the levels of different phases (wood, plastic, zinc borate, and voids) in the composite, and measure the geometry of the wood reinforcement. These outcomes of labeling are noteworthy, but sodium iodide was not an ideal contrast agent because it altered the microstructure of the WPC. For example, it swelled wood particles closing interfacial voids, filled any remaining voids with liquid, and dissolved zinc borate particles. Furthermore, the labeling process was lengthy and two separate CT scans were needed to quantify the composite's composition and analyze the shape of wood reinforcement. Future research should seek to overcome some of these limitations possibly by selecting a solvent for sodium iodide or an alternative halogenated chemical that does not swell wood or dissolve zinc borate. Wood or plastic could be labeled prior to the manufacture of the WPC as has been done previously [21], which would eliminate the time-consuming step of impregnating wood with the contrast agent, but this approach is not suitable for visualizing the microstructure of commercial WPCs, which was one of the aims of this study

Previously, we used X-ray micro-CT to visualize the distribution of the biocide zinc borate in oriented strand board (OSB), a structural wood composite that contains high levels of wood reinforcement and low adhesive content [17]. OSB is manufactured using a completely different process to that of WPCs [32,33], and zinc borate in OSB is located at the interface between wood and adhesive [17]. The distribution of zinc borate in our WPC was different from that in OSB, but in both composites, zinc borate was dissolved by water, which reduced the size of zinc borate particles. The dissolution of zinc borate in WPC and absorption or complexation of zinc or borate ions with wood that is not fully encapsulated in plastic may explain, in part, why it is an effective biocide for WPC's [17]. Some of our findings also help explain other aspects of the durability of WPCs. For example, previous studies, as mentioned above, have shown that WPCs with larger wood particles absorb more moisture and are more susceptible to decay than composites made from smaller particles $[4,34]$. These observations can be explained by our finding that interfacial voids were concentrated around large wood particles and many of the voids were connected, possibly assisting moisture ingress into the WPC, as suggested by Sun et al. [35]. In addition to the network of voids, moisture ingress would also be facilitated by the aggregation of wood particles and the numerous wood-to-wood connections in the composite, which made shape analysis of individual particles difficult. The absorption of moisture into WPCs is the rate-limiting factor restricting decay of the composites [36], and therefore, measures that reduce the porosity of the composite improve the durability of WPCs. In practice, this is achieved in the latest generation of 'capped' WPCs by extruding a layer of pure 
polymer over the surface of the composites [31]. This barrier approach is highly effective at reducing moisture ingress into WPCs, but in areas where the protective polymer cap is absent, or breached, for example by cut ends and fixings, some moisture absorption can still occur [37]. Therefore, additional measures to reduce the porosity and durability of WPCs may be useful. Our results suggest that reducing the number of large wood particles and the interfacial voids around the particles could have the desirable effect of reducing the porosity and possibly increasing the durability of WPCs. Further, research is needed to fully test this hypothesis. Where large wood particles are required as reinforcement for WPCs [38], alternative approaches to reduce the formation of interfacial voids may be needed, for example, modifying wood or plastic to make the two phases more compatible $[39,40]$.

It is difficult to compare our results on the visualization of WPCs with those of previous studies because our approach to labeling the composite has not been used before. However, there is a similarity between the methods we used to analyze the geometry of wood reinforcement and those of previous studies [6,41]. Previous studies have cast doubt on the use of mesh size as an accurate method of characterizing the sizes of wood reinforcement in WPCs. For example, Madyan et al. pointed out that a small mesh allows the passage of long particles, overestimating the potential of small (mesh) particles to reinforce the composite [41]. Our results support this assertion because all the randomly selected particles in our commercial WPC were elongated (aspect ratio: $>2$ ) with a mean aspect ratio of $3.67 ; 28 \%$ of the particles were columnar in shape, and only $30 \%$ of the particles had a centrosymmetric plate-like shape that would allow passage through a mesh in any direction. Previous studies have also used particle diameter as a measure of the size of wood particles used to reinforce WPCs. A diameter measurement is suitable for a sphere, ellipsoid, or cylinder. However, we found that $42 \%$ of the wood particles did not fit these shape categories. Furthermore, wood particles were not spherical because they had a mean sphericity of 0.50 . Therefore, we suggest it would be better in the future to use Feret diameter measurements rather than mesh size or particle diameter to classify the wood reinforcement used to manufacture WPCs. This suggestion is supported by the research of Bacaicoa et al. who obtained Feret-based parameters from wood particles segmented in X-ray micro-CT images [20].

The segmentation of wood particles in a WPC following imaging is a key step in quantifying their shape. This was not straightforward even after our WPC was labeled with sodium iodide. Automated segmentation of wood particles in a WPC was successfully used by Bacaicoa et al. [20], but their WPC had a lower wood content $(10 \%)$ than ours (>50\%) and far less overlap of wood particles. When we tested the same automated software used by Bacaicoa et al. [20], it was unable to find the correct wood particle boundaries because there were numerous overlapping and irregular-shaped particles in our WPC. On the other hand, manual segmentation was too time consuming [42]. These limitations of automated and manual segmentation stimulated the development of our tagging-selecting method, which is more accurate than automated segmentation and less time-consuming than complete manual segmentation. Nevertheless, our approach is still slower than automated segmentation, and it would be desirable to develop an accurate and automated segmentation method for the reinforcement in WPCs. One possible approach involves the use of AI-based techniques, for example, machine learning and neural networking, which have been used to recognize and segment objects automatically in CT images [42,43]. We anticipate that in the future, similar techniques could be used to develop a more advanced automated segmentation algorithm that could recognize the contours of wood particles so that wood particles in commercial WPC samples could be rapidly separated and analyzed. Such developments could facilitate better understanding of the relationships between the geometry of wood reinforcement in WPCs and their properties, possibly leading to the development of improved composites. 


\section{Conclusions}

We showed that aqueous sodium iodide is an effective contrast agent for wood in a commercially manufactured wood plastic composite (WPC), making it possible to clearly visualize both wood and plastic in the WPC, quantify the amounts of wood, plastic, zinc borate, and voids in the composite, and measure the geometry of the wood reinforcement. We described the limitations of sodium iodide as a contrast agent for WPCs and the difficulties of segmenting or separating wood and plastic even in a labeled composite. We suggested methods of overcoming both these limitations using, respectively, nonswelling halogenated contrast agents, and automated machine-learning segmentation algorithms. These advances could lead to a better understanding of the relationships between the microstructure of WPCs and their properties, possibly leading to the development of improved wood plastic composites.

Author Contributions: D.F., M.T. and P.D.E. conceived and designed the experiment; M.T. labeled the wood plastic composite with sodium iodide and performed X-ray micro-CT scans; D.F. visualized the WPC using CT data and performed numerical analyses; P.D.E. and D.F. wrote the first draft of the paper. All three authors discussed and commented on the results and contributed to the final submitted manuscript. All authors have read and agreed to the published version of the manuscript.

Funding: This research was funded in part by the Australian Research Council, grant numbers LP150101040, IC1801000080 and LEO668019.

Institutional Review Board Statement: Not applicable.

Informed Consent Statement: Not applicable.

Data Availability Statement: The data presented in this study are available on request from the corresponding author (D.F.).

Acknowledgments: P.D.E. thanks Viance, Tolko, FPInnovations, the Faculty of Forestry at UBC, and the Government of British Columbia for their support of his BC Leadership Chair in Advanced Forest Products Manufacturing Technology at the University of British Columbia.

Conflicts of Interest: The authors declare no conflict of interest, and none of the individuals or organizations mentioned in the manuscript or acknowledged above were involved in the design of our experiment, collection and interpretation of data, or the writing of this paper.

\section{References}

1. Popescu, C.M. Wood as bio-based building material. In Performance of Bio-Based Building Materials; Brischke, C., Jones, D., Eds.; Woodhead Publishing: Cambridge, UK, 2017; pp. 21-96. [CrossRef]

2. Clemons, C.M.; Rowell, R.M.; Plackett, D.; Segerholm, B.K. Wood/nonwood thermoplastic composites. In Handbook of Wood Chemistry and Wood Composites, 2nd ed.; Rowell, R.M., Ed.; CRC Books: Boca Raton, FL, USA, 2013; pp. 473-508.

3. Wang, Y. Morphological Characterization of Wood Plastic Composite (WPC) with Advanced Imaging Tools: Developing Methodologies for Reliable Phase and Internal Damage Characterization. Master's Thesis, Oregon State University, Corvallis, OR, USA, July 2007.

4. Verhey, S.A.; Laks, P.E. Wood particle size affects the decay resistance of woodfiber/thermoplastic composites. For. Prod. J. 2002, $52,78-81$.

5. Stark, N.M.; Rowlands, R.E. Effects of wood fiber characteristics on mechanical properties of wood/polypropylene composites. Wood Fiber Sci. 2003, 35, 167-174.

6. Chaudemanche, S.; Perrot, A.; Pimbert, S.; Lecompte, T.; Faure, F. Properties of an industrial extruded HDPE-WPC: The effect of the size distribution of wood flour particles. Constr. Build. Mater. 2018, 162, 543-552. [CrossRef]

7. Schwarzkopf, M.J.; Burnard, M.D. Wood-plastic composites-Performance and environmental impacts. In Environmental Impacts of Traditional and Innovative Forest-based Bioproducts; Kutnar, A., Muthu, S., Eds.; Springer: Singapore, 2016; pp. 19-43. [CrossRef]

8. Krause, K.C.; Sauerbier, P.; Koddenberg, T.; Krause, A. Utilization of recycled material sources for wood-polypropylene composites: Effect on internal composite structure, particle characteristics and physico-mechanical properties. Fibers 2018, 6, 86. [CrossRef]

9. Hanhan, I.; Agyei, R.; Xiao, X.; Sangid, M.D. Comparing non-destructive 3D X-ray computed tomography with destructive optical microscopy for microstructural characterization of fiber reinforced composites. Compos. Sci. Technol. 2019, 184, 107843. [CrossRef] 
10. Jezzard, P.; Wiggins, C.J.; Carpnter, T.A.; Hall, L.D.; Jackson, P.; Clayden, N.J.; Walton, N.J. Nuclear magnetic resonance imaging of polymers and polymer composites. Adv. Mater. 1992, 4, 82-90. [CrossRef]

11. Guild, F.J.; Summerscales, J. Microstructural image analysis applied to fibre composite materials: A review. Composites 1993, 24, 383-393. [CrossRef]

12. Young, R.J. Analysis of composites using Raman and fluorescence microscopy-A review. J. Microsc. 1997, 185, 199-205. [CrossRef]

13. Garcea, S.C.; Wang, Y.; Withers, P.J. X-ray computed tomography of polymer composites. Compos. Sci. Technol. 2018, 156, 305-319. [CrossRef]

14. Naresh, K.; Khan, K.A.; Umer, R.; Cantwell, W.J. The use of X-ray computed tomography for design and process modeling of aerospace composites: A review. Mater. Des. 2020, 190, 108553. [CrossRef]

15. Muszynski, L. Imaging wood plastic composites (WPCs): X-ray computed tomography, a few other promising techniques, and why we should pay attention. BioResources 2009, 4, 1210-1221.

16. Evans, P.D.; Morrison, O.; Senden, T.J.; Vollmer, S.; Roberts, R.J.; Limaye, A.; Arns, C.H.; Averdunk, H.; Lowe, A.; Knackstedt, M.A. Visualization and numerical analysis of adhesive distribution in particleboard using X-ray micro-computed tomography. Int. J. Adhes. Adhes. 2010, 30, 754-762. [CrossRef]

17. Evans, P.D.; Lube, V.; Averdunk, H.; Limaye, A.; Turner, M.; Kingston, A.; Senden, T.J. Visualizing the microdistribution of zinc borate in oriented strand board using X-ray microcomputed tomography and SEM-EDX. J. Compos. 2015, 630905. [CrossRef]

18. Paris, J.L.; Kamke, F.A.; Mbachu, R.; Gibson, S.K. Phenol formaldehyde adhesives formulated for advanced X-ray imaging in wood-composite bondlines. J. Mater. Sci. 2014, 49, 580-591. [CrossRef]

19. Kamke, F.A.; McKinley, P.E.; Ching, D.J.; Zauner, M.; Xiao, X. Micro X-ray computed tomography of adhesive bonds in wood. Wood Fiber Sci. 2016, 48, 2-16.

20. Bacaicoa, I.; Lütje, M.; Sälzer, P.; Umbach, C.; Brückner-Foit, A.; Heim, H.P.; Middendorf, B. Comparative investigation of two-dimensional imaging methods and X-ray tomography in the characterization of microstructure. Mater. Test. 2017, 59, 829-836. [CrossRef]

21. Wang, Y.; Muszynski, L.; Simonsen, J. Gold as an X-ray CT scanning contrast agent: Effect on the mechanical properties of wood plastic composites. Holzforschung 2007, 61, 723-730. [CrossRef]

22. Walther, T.; Thoemen, H. Synchrotron X-ray microtomography and 3D image analysis of medium density fiberboard (MDF). Holzforschung 2009, 63, 581-587. [CrossRef]

23. Morrison, O. Resin Distribution in Particleboard. Bachelor's Thesis, The Australian National University, Canberra, Australia, November 2004.

24. Sheppard, A.; Latham, S.; Middleton, J.; Kingston, A.; Myers, G.; Varslot, T.; Fogden, A.; Sawkins, T.; Cruikshank, R.; Saadatfar, M.; et al. Techniques in helical scanning, dynamic imaging and image segmentation for improved quantitative analysis with X-ray micro-CT. Nucl. Instrum. Methods Phys. Res. B 2014, 324, 49-56. [CrossRef]

25. Limaye, A. Drishti: A volume exploration and presentation tool. In Developments in X-ray Tomography VIII; International Society for Optics and Photonics: Bellingham, WA, USA, 2012; Volume 8506, p. 85060X.

26. Siau, J.F. Wood: Influence of Moisture on Physical Properties; Virginia Polytechnic Institute and State University: Blacksburg, VA, USA, 1995.

27. Adebayo, A.B.; Dawson-Andoh, B.; Georg, B.P.; Nkansah, K.; Medley, C. Adsorption and desorption performance of two commercial wood plastic composites. For. Prod. J. 2008, 58, 32-36.

28. Youssef, S.; Rosenberg, E.; Gland, N.F.; Kenter, J.A.; Skalinski, M.; Vizika, O. High resolution CT and pore-network models to assess petrophysical properties of homogeneous and heterogeneous carbonates. In Proceedings of the 2007 SPE/EAGE Reservoir Characterization and Simulation Conference, Abu Dhabi, United Arab Emirates, 28 October 2007; p. 111427.

29. Wadell, H. Volume, shape, and roundness of quartz particles. J. Geol. 1935, 43, 250-280. [CrossRef]

30. Merkus, H.G. Particle Size Measurements: Fundamentals, Practice, Quality; Springer: Pijnacker, The Netherlands, 2009.

31. Mankowski, M.E.; Manning, M.J.; Slowik, D.P. Durability of capped wood plastic composites. In Proceedings of the 111th Annual Meeting of the American Wood Protection Association, Asheville, NC, USA, 12-14 April 2015; pp. 124-132.

32. Lötter, B.T.; Evans, P.D. Sprayable hot melt waxes as water repellents for oriented strand board. Int. Wood Prod. J. 2019, 10, 102-110. [CrossRef]

33. Gardner, D.J.; Han, Y.; Wang, L. Wood-plastic composite technology. Curr. For. Rep. 2015, 1, 139-150. [CrossRef]

34. Steckel, V.; Clemons, C.M.; Thoemen, H. Effects of material parameters on the diffusion and sorption properties of woodflour/polypropylene composites. J. Appl. Polym. Sci. 2007, 103, 752-763. [CrossRef]

35. Sun, G.; Ibach, R.E.; Faillace, M.; Gnatowski, M.; Glaeser, J.A.; Haight, J. Laboratory and exterior decay of wood-plastic composite boards: Voids analysis and computed tomography. Wood Mater. Sci. Eng. 2016, 12, 263-278. [CrossRef]

36. Morrell, J.J.; Stark, N.M. Durability of wood-plastic composites. Wood Des. Focus 2006, 16, 7-10.

37. Gnatowski, M.; Ibach, R.; Leung, M.; Sun, G. Magnetic resonance imaging used for the evaluation of water presence in wood plastic composite boards exposed to exterior conditions. Wood Mater. Sci. Eng. 2015, 10, 94-111. [CrossRef]

38. Chen, H.C.; Chen, T.Y.; Hsu, C.H. Effects of wood particle size and mixing ratios of HDPE on the properties of the composites. Holz Als Roh Werkst. 2006, 64, 172-177. [CrossRef] 
39. Takatani, M.; Ikeda, K.; Sakamoto, K.; Okamoto, T. Cellulose esters as compatibilizers in wood/poly(lactic acid) composite. J. Wood Sci. 2008, 54, 54-61. [CrossRef]

40. Lin, H.; Li, R.; Li, D.; Huang, Z.; Pang, J.; Zhang, X.; Liu, W.; Yang, W. Hydrophobic wood flour derived from a novel p-TsOH treatment for improving interfacial compatibility of wood/HDPE composites. Cellulose 2020, 27, 4053-4065. [CrossRef]

41. Madyan, O.A.; Wang, Y.; Corker, J.; Zhou, Y.; Du, G.; Fan, M. Classification of wood fibre geometry and its behaviour in wood poly(lactic acid) composites. Composite A 2020, 133, 105871. [CrossRef]

42. Strohmann, T.; Bugelnig, K.; Breitbarth, E.; Wilde, F.; Steffens, T.; Germann, H.; Requena, G. Semantic segmentation of synchrotron tomography of multiphase Al-Si alloys using a convolutional neural network with a pixel-wise weighted loss function. Sci. Rep. 2019, 9, 19611. [CrossRef] [PubMed]

43. Furat, O.; Wang, M.; Neumann, M.; Petrich, L.; Weber, M.; Krill, C.E.; Schmidt, V. Machine learning techniques for the segmentation of tomographic image data of functional materials. Front. Mater. 2019, 6, 145. [CrossRef] 